Asten, L. van, Siebenga, J., Wijngaard, C. van den, Verheij, R., Vliet, H. van, Kretzschmar, M., Boshuizen, H., Pelt, W. van, Koopmans, M. Unspecified gastroenteritis illness and deaths in the elderly associated with norovirus epidemics. Epidemiology: 2011, 22(3), 336-343

\begin{tabular}{|l|c|}
\hline Postprint Version & 1.0 \\
\hline Journal website & $\begin{array}{c}\text { http://journals.lww.com/epidem/pages/articleviewer.aspx?year=2011\&issue }=05 \\
\text { 000\&article=00013\&type=abstract }\end{array}$ \\
\hline Pubmed link & http://www.ncbi.nlm.nih.gov/pubmed/21358409 \\
\hline DOI & $10.1097 /$ EDE.0b013e31821179af \\
\hline
\end{tabular}

This is a NIVEL certified Post Print, more info at http://www.nivel.eu

\title{
Unspecified Gastroenteritis Illness and Deaths in the Elderly Associated With Norovirus Epidemics
}

\author{
LiselotTe VAN ASTEN, ${ }^{\mathrm{A}}$ JoUkJe SieBenga, ${ }^{\mathrm{A}, \mathrm{D}}$ CEES VAN DEN WiJNGAARD, ${ }^{\mathrm{A}}$ ROBERT VERHEIJ, ${ }^{\mathrm{C}}$ HANS VAN \\ VLIET, ${ }^{\mathrm{A}}$ MIRJAM KRETZSCHMAR, ${ }^{\mathrm{A}}$ HENDRIEK BOSHUIZEN, ${ }^{\mathrm{B}}$ WILFRID VAN PELT, ${ }^{\mathrm{A}}$ AND MARION \\ KOOPMANS ${ }^{\mathrm{A}, \mathrm{D}}$
}

From the aCentre for Infectious Disease Control Netherlands, National Institute for Public Health and the Environment, Bilthoven, The Netherlands; bExpertise Centre for Methodology and Information Services, National Institute for Public Health and the Environment, Bilthoven, The Netherlands; cNetherlands Institute of Health Services Research (NIVEL), Utrecht, The Netherlands; and dDepartment of Virology, Erasmus Medical Center, Rotterdam, The Netherlands.

Background: New variant strains of norovirus have emerged worldwide in recent years, evolving by mutation much like influenza viruses. These strains have been associated with a notable increase in the number of annual norovirus outbreaks. However, the impact of such increased norovirus activity on morbidity and mortality is not clear because norovirus infection is rarely specifically registered.

Methods: We studied trends of gastroenteritis with unspecified cause in medical registrations (ie, general practitioner [GP] visits, hospitalizations, and deaths) and their association with known temporal trends in norovirus outbreaks in the Netherlands. Using weekly counts in the elderly (aged 65+ years) from 1999 through 2006, we applied Poisson regression analyses adjusted for additional pathogens and seasonal trends (linear, sine, and cosine terms).

Results: In the elderly, each notified norovirus outbreak was associated with an estimated 26 unspecified gastroenteritis GP visits $(95 \%$ confidence interval $=17-34), 2.2$ unspecified gastroenteritis hospitalizations (1.6-2.7), and 0.14 unspecified gastroenteritis deaths (0.080.21). For the heaviest norovirus season (2004-2005), these models attributed up to 3804 unspecified gastroenteritis GP visits, 318 unspecified gastroenteritis hospitalizations, and 21 unspecified gastroenteritis deaths to norovirus outbreaks among a total elderly population of 2.3 million.

Discussion: The recent increase in norovirus outbreak activity is associated with increases of unspecified gastroenteritis morbidity and even deaths in the elderly. Norovirus should not be regarded as an infection with trivial health risks.

Diarrheal disease has been linked to increased mortality among the elderly, especially in winter.1 This seasonal rise suggests that, in regions of temperate climate, a putative cause may be infections with norovirus, which typically peak in the winter.2 Norovirus infection, or "winter vomiting disease," is a common cause of community-acquired sporadic cases and outbreaks of acute gastroenteritis, with vomiting and diarrhea being the characteristic symptoms.3-5 Noroviruses are highly infectious and are notorious for causing outbreaks in semi-closed communities such as nursing homes.6 Although symptomatic infection is generally regarded as mild, data indicate that severe disease - including dehydrating diarrhea requiring 
Asten, L. van, Siebenga, J., Wijngaard, C. van den, Verheij, R., Vliet, H. van, Kretzschmar, M., Boshuizen, H., Pelt, W. van, Koopmans, M. Unspecified gastroenteritis illness and deaths in the elderly associated with norovirus epidemics. Epidemiology: 2011, 22(3), 336-343

hospitalization, and perhaps even death-occurs in vulnerable populations such as infants in developing countries, the elderly, and the immunocompromised.7-10 The extent of morbidity and mortality posed by norovirus infections among the elderly is unclear and probably underestimated.11 Norovirus epidemiology has changed remarkably in recent years. In 2002, a genetic shift in circulating strains was observed with the global emergence of the GII.4-2002 norovirus variant. This coincided with an unusually high number of outbreaks worldwide in winter 2002-2003, preceded by off-seasonal norovirus activity in spring 200212,13 with reported outbreaks more than doubling across Europe.14 In 2004, another genetic variant (GII.4-2004 strain) emerged, followed by high norovirus activity, and in 2006, 2 novel variants emerged (GII.4- 2006a and -2006b), which again coincided with an exceptionally high number of outbreaks starting early spring 2006.6,15,16 Information from our ongoing norovirus-outbreak surveillance captured 3 recent winters with heavy norovirus activity and included information on genotypes. This permitted unique exploration of norovirus outbreak activity and its association with nationwide gastroenteritis morbidity and mortality based on medical registrations of general practitioner (GP) consultations, hospitalizations, and deaths for an 8-year period (1999-2006).

Because norovirus laboratory testing is uncommon and the health burden of norovirus infections is unknown, a study of medical diagnoses and causes of death of unspecified gastroenteritis (ie, of unknown causative pathogen) allowed us to estimate the proportion of unspecified gastroenteritis that is attributable to norovirus activity, in particular for the heavy outbreak seasons of 2002-2003, 2004-2005, and 20052006.

\section{METHODS}

To study the association of norovirus independent of other agents with morbidity and mortality at the population level, we analyzed time series from 5 data sources (Table 1).

These series reflect weekly counts of selected gastrointestinal complaints or diagnoses from registries in the Netherlands.

Because norovirus testing 17 is not common in general practices or in hospitals (coding systems do not refer specifically to norovirus infection), cases are rarely registered, even if recognized. Instead, they are coded into a category for infectious or viral gastroenteritis (probably most labeled to be of unknown etiology). We have grouped such categories under "unspecified gastroenteritis," as seen in 3 of the 5 data sources that follow.

\section{1) Norovirus Outbreak Surveillance}

Information for 13 years of norovirus outbreaks (1994-2006) was acquired from the Dutch national norovirus outbreak surveillance system, initiated in 1994. A cluster of two or more epidemiologically linked cases was considered an outbreak. In this surveillance, a minimal set of data is collected for each reported outbreak and combined with results from molecular-biologic detection and typing techniques.6,18,19

\section{2) Unspecified Gastroenteritis in General Practitioner Consultations}

A diagnosis of a "suspected gastro-intestinal infection" (International Classification of Primary Care _ICPC_code D73) was defined as unspecified gastroenteritis. Vomiting and diarrhea (both common in norovirus infection, ICPCcodes D10 and D11) were considered separately. GP consultation data came from a representative sentinel network of GPs, the Netherlands Information Network of General Practice, covering 2\% of the Dutch population between 2001 and 2006.20,21 Virtually all Dutch citizens, including those in homes for the elderly, are registered with a GP (ie, family physician), their first point of contact with the Dutch health care system. Persons in nursing homes are alternatively grouped with a nursing home GP.

\section{3) Unspecified Gastroenteritis in Hospitalizations}

A hospital discharge diagnosis (primary or secondary) of gastroenteritis designated to be of viral or of infectious etiology but not clearly specified was defined as unspecified gastroenteritis (International Classification of Diseases, ninth revision _ICD9_, codes 0086, 0088, 0090-0091, 0059, and 5589). We also included discharge diagnoses registered as "Other and unspecified noninfectious gastroenteritis" (ICD9: 5589), as this code is known to consist of a large viral gastroenteritis infectious component, not registered 
Asten, L. van, Siebenga, J., Wijngaard, C. van den, Verheij, R., Vliet, H. van, Kretzschmar, M., Boshuizen, H., Pelt, W. van, Koopmans, M. Unspecified gastroenteritis illness and deaths in the elderly associated with norovirus epidemics. Epidemiology: 2011, 22(3), 336-343

or recognized as such.22 Data were obtained from the Dutch National Medical Register, which covered 99\% of the Dutch population (16.3 million), between 1999 and 2006.

\section{4) Unspecified Gastroenteritis in Mortality Data}

Causes of death attributed to viral gastroenteritis (A081-A089) and infectious gastroenteritis (A091A099, International Classification of Diseases and Related Health Problems, or ICD10) were defined as unspecified gastroenteritis deaths, with data from 1999 to 2006. Both primary and secondary causes of death were considered. The code A081 designates norovirus as a cause of death but was applied to only one person during the whole study period (eAppendix 1, http://links.lww.com/EDE/A459). Our mortality statistics originate from Statistics Netherlands and cover the total Dutch population.

\section{5) Classic Laboratory Surveillance}

From laboratory surveillance, we used positive results of diagnostic tests for infectious pathogens that can cause gastrointestinal complaints. We used time series (1999-2006) for influenza (estimated proportion of all diagnostics captured by national surveillance $73 \%$ ), rotavirus (38\%), Salmonella (64\%), Campylobacter $(50 \%)$, and Shigella (100\%).23 The time series are assumed representative for the Dutch population of all ages.

\section{Study Population}

Graphic representation and analyses of trends were restricted to persons 65 years and older, except for laboratory surveillance data and norovirus outbreak data (which do not provide data on age). However, most norovirus outbreaks occur in nursing homes, and thus in the elderly. The gastroenteritis morbidity pattern in the elderly differs from that in children, whose gastroenteritis hospitalization rates are dominated by rotavirus activity. 22,24

\section{Statistical Analyses}

We plotted monthly time series of unspecified gastroenteritis trends in the elderly. On weekly data, we used Poisson regression models (which included linear and periodic components) to characterize various trends: model (1) unspecified gastroenteritis GP consultations explained by a combination of a linear trend, a seasonal trend, norovirus outbreak activity, and other pathogens from laboratory surveillance; model (2) unspecified gastroenteritis hospitalizations explained by the same variables as given for model 1; and model (3) unspecified gastroenteritis deaths explained by the same variables as given for model 1.

We used the following equation:

Unspecified gastroenteritis $\mathrm{t}_{\mathrm{t}}$

$\sim \operatorname{Poisson}\left(\lambda_{t}\right)$

$\lambda_{\mathrm{t}}=\beta_{0}+\beta_{1 \mathrm{t}}+\beta_{2} \sin \left(2 \pi_{\mathrm{t}} / 52\right)+\beta_{3} \cos (2 \pi / 52)+\beta_{4} \mathrm{P}_{1,(\mathrm{t}-\operatorname{lagP} 1)}+\beta_{5} \mathrm{P}_{2,(\mathrm{t}-\operatorname{lagP} 2)}+\ldots+\beta_{\mathrm{m}} \mathrm{P}_{\mathrm{k},(\mathrm{t}-\operatorname{lagPk})}$

(See eAppendix 2 http://links.lww.com/EDE/A459 for the definitions of all terms.)

\section{[TABLE 1]}

\section{[FIGURE 1]}

This statistical model is similar to time series models for other illnesses, such as hospital admissions attributable to rotavirus activity,22,25 and deaths attributable to influenza and respiratory syncytial virus.26 We incorporated seasonal trends because many health variables show systematic variation over the course of a year, even if these variables are not causally related.27 We used a generalized linear model with an overdispersed Poisson-distributed error, and an identity link (with the addition of a scale parameter to take overdispersion into account). We assumed that each weekly pathogen count was associated with a constant number of unspecified gastroenteritis cases throughout the study period (ie, regression coefficients: $\beta 4, \beta 5$, etc not varying with time).

$\beta 0$ is the estimated constant level of weekly registered gastroenteritis not explained by the variation in pathogen trends or the seasonal trends included in the model. We did not include the population at risk in the model, as the population increase in this period is moderate. Any increasing trend will be taken into account by the linear term in our model (ß1).

For each parameter, we computed Wald 95\% confidence intervals (CIs). 
Asten, L. van, Siebenga, J., Wijngaard, C. van den, Verheij, R., Vliet, H. van, Kretzschmar, M., Boshuizen, H., Pelt, W. van, Koopmans, M. Unspecified gastroenteritis illness and deaths in the elderly associated with norovirus epidemics. Epidemiology: 2011, 22(3), 336-343

For each model, we checked for a statistically significant increasing or decreasing linear trend with time and a significant seasonal trend (sine and cosine terms). Using a forward stepwise selection, we checked which additional explanatory variables (norovirus outbreaks and other pathogen counts) contributed significantly to the trends in the outcome variables (defined as unspecified gastroenteritis GP consultations, unspecified gastroenteritis hospitalizations, or unspecified gastroenteritis mortality). We also evaluated the association with the lagged values of norovirus outbreaks and the other pathogens (up to 4 weeks backwards in time), building each increment in the model by adding all possible lags of all pathogens and selecting the lag with the best fit (assessed with the deviance), until no more pathogens contributed significantly to the model. In the final model, each pathogen, appropriately lagged, was included in the model only once. To avoid over-modeling of the data, negative associations were not included with the underlying consideration that pathogens can cause disease but generally do not decrease disease burden.

\section{RESULTS}

\section{Norovirus Outbreaks on the Rise}

Data on the frequency and starting dates of reported norovirus outbreaks, available since 1994, are detailed elsewhere.

6 Outbreaks occur mostly in the winter season (October- March). The 3 recent winter seasons of 20022003, 2004-2005, and 2006-2007 stand out in these time series, with well over 100 confirmed norovirus outbreaks in each season. Although only the beginning of the 2006-2007 winter was included in our study period, the weekly number of reported outbreaks was also relatively high (Fig. 1). The norovirus time series did not coincide with known trends in any other monitored enteric pathogen, or with influenza (which occasionally causes gastroenteritis symptoms) (Fig.

1). For most norovirus outbreaks (95\%), the month of occurrence was known; for $72 \%$, the week was also available. As the missing weeks were distributed equally over the observed years, the trend is similar whether based on monthly or weekly data (data not shown).

\section{Trends in Unspecified Gastroenteritis Illness}

\section{(Seen at GPs and Hospitalizations)}

Marked elevations of unspecified gastroenteritis among the elderly were seen in both GP consultations and in hospitalizations, coinciding with all 3 heavy epidemic norovirus peaks (winter 2002-2003, 2004-2005, and 2005-2006, eAppendices 3 and 4 http://links.lww.com/EDE/A459_). The average monthly incidence of unspecified gastroenteritis registered by sentinel physicians increased $70 \%-240 \%$ above average at the height of the 3 unusual norovirus peaks (overall average: 91/100,000 elderly individuals, increasing to 150 , 171, and 217, respectively) (eAppendix 3). A similar trend, although less extreme, was seen for hospitalizations, with incidence of unspecified gastroenteritis increasing more than $30 \%$ above average during the 3 epidemic norovirus outbreaks (the overall average monthly incidence of unspecified gastroenteritis was 19/100,000, peaking at 24,27, and 26 per 100,000 elderly in the epidemic seasons, eAppendix 4).

Such peaks in unspecified morbidity were seen at no other time in unspecified gastroenteritis hospitalizations, and at only one other time in unspecified gastroenteritis GP consultations (April 2004, coinciding with rotavirus season).

In multivariate regression models, norovirus outbreaks were a significant predictor of both the number of unspecified gastroenteritis GP consultations and the number of unspecified gastroenteritis hospitalizations (see Table 2 for model parameters). In the model of unspecified gastroenteritis GP consultations, the beta for norovirus was $0.51(95 \% \mathrm{CI}=0.33-0.67)$. With the GP-sentinel data representing $2 \%$ of the Dutch population, we estimate this beta to be approximately 50 times higher for the total population $(25.7$, ie, estimating approximately 25 unspecified gastroenteritis GP visits for every norovirus outbreak, Table 2), thus attributing over 11,000 unspecified gastroenteritis GP visits to norovirus activity over a 5-year period (the majority occurring in the 3 epidemic years: eg, 3804 attributed to the epidemic year of 2004-2005, Table 3). The beta for unspecified gastroenteritis hospitalizations was $2.15(1.57-2.74)$, thus attributing 215-318 unspecified gastroenteritis hospitalizations to norovirus activity in the 3 epidemic years (Table 3 ). 
Asten, L. van, Siebenga, J., Wijngaard, C. van den, Verheij, R., Vliet, H. van, Kretzschmar, M., Boshuizen, H., Pelt, W. van, Koopmans, M. Unspecified gastroenteritis illness and deaths in the elderly associated with norovirus epidemics. Epidemiology: 2011, 22(3), 336-343

While the unspecified gastroenteritis trend in both GP and hospital data clearly coincided with norovirus activity, the GP consultations for vomiting or diarrhea (both symptoms that can occur with numerous illnesses) showed no clear trends.

\section{[TABLE 2]}

\section{Trends in Unspecified Gastroenteritis Deaths}

A total of 551 deaths with unspecified gastroenteritis as primary or secondary cause were registered in 1999-2006 in the elderly (an average monthly incidence of 2.6 deaths per million inhabitants 65 years and older). As with unspecified gastroenteritis morbidity, unspecified gastroenteritis deaths also rose during the 3 norovirus epidemics (eAppendix 5, http://links.lww.com/EDE/A459), with the monthly rate rising to above 6 per million during the norovirus seasons (even peaking at 8.2 per million in the 2002-2003 winter). Unspecified gastroenteritis was coded as the primary cause of death $(n=437)$ more often than as secondary cause ( $\mathrm{n}=114$, eAppendix 2, http://links.lww.com/EDE/A459), but both showed the same temporal trend. The number of deaths in the 2 subclassifications of unspecified gastroenteritis deaths (A08, "viral intestinal infection" and A09, "gastroenteritis of presumed infectious origin") were roughly equal, with $26 \%$ more deaths coded in the latter ( 280 vs. 354 for all age groups combined) during the 8-year study period.

The peaks in mortality during the 2 norovirus epidemics did not seem to coincide with known seasons of influenza or infections with rotavirus, Salmonella, Shigella, or Campylobacter (Fig. 1). Indeed, when modeling-unspecified gastroenteritis deaths by laboratory counts of enteric pathogens (and correcting for a linear and seasonal trend with time) norovirus activity ( 1 weeks previously) remained as the single pathogen with significant predictive value (Fig. 2). The beta for norovirus was 0.14 (95\% CI, $0.08-0.21$; Table 3), ie, one death registered as unspecified gastroenteritis for every 7 outbreaks. Of all 551 unspecified gastroenteritis deaths, 79 in the elderly were thus statistically attributed to norovirus over the 8-year period (Table 3 and Fig. 2). The remaining gastropathogens did not significantly improve the model, nor did influenza. Whether these deaths were among persons with extreme comorbidity is not known, as we had no data on comorbidity.

\section{[TABLE 3]}

[FIGURE 2]

\section{DISCUSSION}

Norovirus gastroenteritis is generally viewed as a trivial illness of short duration. This study, using population-based databases, suggests that the overall public health consequences of norovirus have been underestimated: extreme outbreak activity (in the 2002-2003, 2004-2005, and 2005-2006 winters) due to the introduction of new strains 12 coincided with sharp increases of unspecified gastroenteritis morbidity, hospitalizations, and even deaths in the Dutch elderly population.

We know of no other published data that estimate the impact of norovirus outbreaks at various public health levels: from milder illness (presenting to general practitioners), to severe illness (presenting at or during hospitalizations), and deaths. That norovirus is associated not only with morbidity but with deaths in the elderly may come as a surprise, considering that norovirus is regarded as an illness with a low casefatality rate. $28 \mathrm{~A}$ few recent - mostly anecdotal — reports have suggested that norovirus infections may be more severe in the elderly. Nursing homes in Japan,29 the United States, Israel, and the Netherlands reported unexpected numbers of deaths during norovirus outbreaks in the absence of any influenza activity.30-33 A study in England and Wales estimated only one death for every 50 outbreaks, 9 but these data were acquired before the worldwide emergence of the recent epidemic norovirus variants 12 and considered only persons within the outbreaks, not the total exposed and infected population.

In the Netherlands, gastroenteritis deaths suddenly increased after the striking epidemic norovirus season of 2002-2003.34 In total, our models estimated up to 21 yearly unspecified gastroenteritis deaths, 318 hospitalizations, and 3804 GP visits attributable to norovirus activity in the heavy 2004- 2005 norovirus season. This number of deaths is comparable to a recent estimate from the United Kingdom.35 Although our study suggests morbidity and mortality attributable to norovirus activity, our estimates may still represent an underestimation of the actual situation. Illness and deaths due to infectious gastroenteritis are poorly recognized and underreported.

36-38 Frenzen36 suggests a roughly 12 -fold underestimation. 
Asten, L. van, Siebenga, J., Wijngaard, C. van den, Verheij, R., Vliet, H. van, Kretzschmar, M., Boshuizen, H., Pelt, W. van, Koopmans, M. Unspecified gastroenteritis illness and deaths in the elderly associated with norovirus epidemics. Epidemiology: 2011, 22(3), 336-343

It can be difficult to ascertain which illnesses and underlying diseases in the elderly contribute to death. The coding of causes of death (as is done for registration purposes) may underestimate the contribution of a complication such as a viral infection. A recent Dutch study to identify direct causes of deaths focused on the last 2 days of life of nursing home patients, and showed that dehydration (ie, disorders of electrolyte and fluid balance), while reversible, is among the 3 most common causes of death.39 Such symptoms or consequences, which can accompany a norovirus infection, remain largely unidentified or unregistered as a (contributing) cause of death. In our model, the highest correlation between norovirus and unspecified gastroenteritis deaths was found with a lag of 1 week, suggesting that norovirus outbreaks preceded unspecified gastroenteritis deaths by 1 week. For hospitalizations, the strongest association was with a lag of 3 weeks, whereas, at the overall community level, gastroenteritis complaints seen by GPs presented simultaneously with the emergence of norovirus outbreaks (as illustrated by an optimal delay of 0 weeks in the model). To explain the difference in lag time between hospitalizations and deaths ( 3 weeks vs. 1 week), we hypothesize that, although norovirus infection may trigger death relatively rapidly in very frail persons, in the less frail elderly population, the virus might be introduced later (nursing homes, with the frailest populations, are notorious for outbreaks) or it may trigger a slower deterioration of health or a slower aggravation of underlying illnesses.

The fact that epidemic norovirus years show an association with increased illness and death, might suggest that new viral strains have increased pathogenicity. This cannot be proven on the basis of the observations in this study. New variants might cause greater numbers of disease simply due to a larger pool of susceptible persons in whom immunity has not yet developed. Recent evidence suggests that host immunity does play a role in norovirus evolution, with the GII.4 variants being antigenic variants.6,12,40-42 A limitation of our study is our assumption that all circulating pathogens other than norovirus are also tested for during the winter months. The absence of data does not necessarily mean the absence of other pathogens, in which case our betas for norovirus may have been overestimated.

Other surveillance artifacts could also play a role in an ecologic analysis 43 such as ours. Still, the consistency of trends across all 4 medical registrations (norovirus surveillance, GP consultations, hospitalizations, and deaths) supports the hypothesis that norovirus epidemics are associated with morbidity and death in the elderly, and that these trends may be influenced by viral evolution. Furthermore, other countries also registered high peaks of norovirus activity in the same epidemic years. In addition to heightened awareness and improved reporting, the increased number of outbreaks in the Netherlands has been demonstrated to be a true rise caused by continually emerging novel variants of norovirus.44,45 However, for the medical registries, reporting bias can not be ruled out entirely. Another potential confounder of our results is Clostridium difficile ribotype 027 infections, which are associated with high mortality.

However, the emergence of this type in the Netherlands was first noted in 2005,46 after the first epidemic season (2002-2003) of norovirus included in our data. Furthermore, C. difficile infections in the Netherlands are not known to exhibit a clear seasonal trend. There are no known changes of coding practices over time, and coding systems were consistent over the study years within each registry (ICPC codes for GP data, ICD9 codes Dutch version for hospitalizations, and ICD10 codes for the death registry).

Norovirus outbreaks are common and mostly are considered a nuisance. Our findings, coupled with recent reports of chronic disease due to norovirus infections in persons with comorbidities 47,48 and the epidemic behavior of the novel GII.4 variants, 45 suggest that the impact of norovirus disease on public health may have been underestimated. The numbers are substantial and warrant further investigation. Further research should also investigate to what extent the prevention of norovirus infection improves longevity in the elderly - either by hygiene and isolation measures or by treatment. With such a rapidly evolving virus, vigilant monitoring of outbreaks and the molecular evolution of the virus remains crucial.

\section{ACKNOWLEDGMENTS}

We thank Yvonne van Duynhoven, Annelies Kroneman, and Erwin Duizer (National Institute for Public Health and the Environment, RIVM) for critical reading of the manuscript; Dutch Hospital Data for providing data from the Dutch National Medical Register (LMR); Statistics Netherlands (CBS) for providing data; members of the Dutch 
Asten, L. van, Siebenga, J., Wijngaard, C. van den, Verheij, R., Vliet, H. van, Kretzschmar, M., Boshuizen, H., Pelt, W. van, Koopmans, M. Unspecified gastroenteritis illness and deaths in the elderly associated with norovirus epidemics. Epidemiology: 2011, 22(3), 336-343

Working Group on Clinical Virology for collecting and providing weekly positive diagnostic results; and Lucy Phillips

for editorial consultation on the manuscript.

\section{REFERENCES}

1. Lew JF, Glass RI, Gangarosa RE, Cohen IP, Bern C, Moe CL. Diarrheal deaths in the United States, 1979 through 1987. A special problem for the elderly. JAMA. 1991;265:3280 -3284.

2. Mounts AW, Ando T, Koopmans M, Bresee JS, Noel J, Glass RI. Cold weather seasonality of gastroenteritis associated with Norwalk-like viruses.

J Infect Dis. 2000;181(suppl 2):S284 -S287.

3. De Wit MA, Koopmans MP, Kortbeek LM, et al. Sensor, a populationbased cohort study on gastroenteritis in the Netherlands: incidence and etiology. Am J Epidemiol. 2001;154:666-674.

4. Patel MM, Widdowson MA, Glass RI, Akazawa K, Vinje J, Parashar UD. Systematic literature review of role of noroviruses in sporadic gastroenteritis. Emerg Infect Dis. 2008;14:1224 -1231.

5. Wheeler JG, Sethi D, Cowden JM, et al. Study of infectious intestinal disease in England: rates in the community, presenting to general practice, and reported to national surveillance. The Infectious Intestinal Disease Study Executive. BMJ. 1999;318:1046 -1050.

6. Siebenga JJ, Vennema H, Duizer E, Koopmans MP. Gastroenteritis caused by norovirus GGII. 4, The Netherlands, 1994-2005. Emerg

Infect Dis. 2007;13:144-146.

7. Gangarosa RE, Glass RI, Lew JF, Boring JR. Hospitalizations involving gastroenteritis in the United States, 1985: the special burden of the disease among the elderly. Am J Epidemiol. 1992;135:281-290.

8. Patel MM, Hall AJ, Vinje J, Parashar UD. Noroviruses: a comprehensive review. J Clin Virol. 2009;44:18.

9. Lopman BA, Adak GK, Reacher MH, Brown DW. Two epidemiologic patterns of norovirus outbreaks: surveillance in England and Wales, 1992-2000. Emerg Infect Dis. 2003;9:71-77.

10. Mattner F, Sohr D, Heim A, Gastmeier P, Vennema H, Koopmans M.

Risk groups for clinical complications of norovirus infections: an outbreak investigation. Clin Microbiol Infect. 2006;12:69-74.

11. Strausbaugh LJ, Sukumar SR, Joseph CL. Infectious disease outbreaks in nursing homes: an unappreciated hazard for frail elderly persons. Clin

Infect Dis. 2003;36:870-876.

12. Lopman $B$, Vennema $H$, Kohli $E$, et al. Increase in viral gastroenteritis outbreaks in Europe and epidemic spread of new norovirus variant.

Lancet. 2004;363:682- 688.

13. Anderson L. Norovirus activity—United States, 2002. Morb Mortal

Wkly Rep. 2003;52:41- 45.

14. Koopmans $\mathrm{M}$, Vennema $\mathrm{H}$, Heersma $\mathrm{H}$, et al. Early identification of common-source foodborne virus outbreaks in Europe. Emerg Infect Dis.

2003;9:1136 -1142.

15. Siebenga J, Kroneman A, Vennema H, Duizer E, Koopmans M. Foodborne viruses in Europe network report: the norovirus GII. 4 2006b (for US named Minerva-like, for Japan Kobe034-like, for UK V6) variant now dominant in early seasonal surveillance. Euro Surveill. 2008;13: pii_8009.

16. Bull RA, Tu ET, Mclver CJ, Rawlinson WD, White PA. Emergence of a new norovirus genotype II. 4 variant associated with global outbreaks of gastroenteritis. J Clin Microbiol. 2006;44:327-333.

17. Marshall JA, Bruggink LD. Laboratory diagnosis of norovirus. Clin Lab.

2006;52:571-581.

18. Vennema $H$, de Bruin E, Koopmans $M$. Rational optimization of generic primers used for Norwalk-like virus detection by reverse transcriptase polymerase chain reaction. J Clin Virol. 2002;25:233-235.

19. Vinje J, Koopmans MP. Molecular detection and epidemiology of small round-structured viruses in outbreaks of gastroenteritis in the Netherlands.

$\mathrm{J}$ Infect Dis. 1996;174:610-615.

20. Verheij R, Van der Zee J. Collecting information in general practice: "just by pressing a single button?" In: Westert GP, Jabaaij L, Schellevis FG, eds. Morbidity, Performance and Quality in Primary Care. Dutch General Practice on Stage. Oxford, Seattle: Radcliffe Publishing; 2006.

21. Verheij RA. Netherlands Information Network of General Practice.

Facts and figures about general practitioner care in the Netherlands _web page_. Available at: http:/www.LINH.nl.

22. De Wit MA, Koopmans MP, van der Blij JF, van Duynhoven YT. 
Asten, L. van, Siebenga, J., Wijngaard, C. van den, Verheij, R., Vliet, H. van, Kretzschmar, M., Boshuizen, H., Pelt, W. van, Koopmans, M. Unspecified gastroenteritis illness and deaths in the elderly associated with norovirus epidemics. Epidemiology: 2011, 22(3), 336-343

Hospital admissions for rotavirus infection in the Netherlands. Clin

Infect Dis. 2000;31:698 -704.

23. Van den Brandhof WE, Kroes AC, Bosman A, Peeters MF, Heijnen ML.

Reporting virus diagnostics in the Netherlands: representativeness of the virological weekly reports _in

Dutch_. Infectieziekten Bull. 2002;13: 110-113.

24. Van Damme P, Giaquinto C, Huet F, Gothefors L, Maxwell M, Van der Wielen M. Multicenter prospective study of the burden of rotavirus acute gastroenteritis in Europe, 2004-2005: The REVEAL Study. J Infect Dis.

2007;195(suppl 1):S4 -S16.

25. Ryan MJ, Ramsay M, Brown D, Gay NJ, Farrington CP, Wall PG.

Hospital admissions attributable to rotavirus infection in England and Wales. J Infect Dis. 1996;174(suppl

1):S12-S18.

26. Gay NJ, Andrews NJ, Trotter CL, Edmunds WJ. Estimating deaths due to influenza and respiratory syncytial virus. JAMA. 2003;289:2499; author reply 2500-2502.

27. Schwartz J, Spix C, Touloumi G, et al. Methodological issues in studies of air pollution and daily counts of deaths or hospital admissions.

J Epidemiol Community Health. 1996;50(suppl 1):S3-S11.

28. Olsen SJ, MacKinnon LC, Goulding JS, Bean NH, Slutsker L.

Surveillance for foodborne-disease outbreaks-United States, 1993- 1997. MMWR CDC Surveill Summ. 2000;49:1- 62.

29. Okada M, Tanaka T, Oseto M, Takeda N, Shinozaki K. Genetic analysis of noroviruses associated with fatalities in healthcare facilities. Arch

Virol. 2006;151:1635-1641.

30. Wu HM, Fornek M, Schwab KJ, et al. A norovirus outbreak at a long-term-care facility: the role of environmental surface contamination.

Infect Control Hosp Epidemiol. 2005;26:802- 810.

31. Centers for Disease Control and Prevention. Norovirus activity—United States, 2006-2007. Morb Mortal Wkly Rep. 2007;56:842- 846. Abstract.

32. Calderon-Margalit R, Sheffer R, Halperin T, Orr N, Cohen D, Shohat T.

A large-scale gastroenteritis outbreak associated with norovirus in nursing homes. Epidemiol Infect. 2005;133:35- 40.

33. Rondy M, Koopmans M, Rotsaert C, et al. Norovirus disease associated with excess mortality and use of statins: a retrospective cohort study of an outbreak following a pilgrimage to Lourdes. Epidemiol Infect. 2011; 139:453- 463.

34. Van Asten L, van den Wijngaard C, Siebenga J, van Pelt W, van Vliet H, Koopmans M. Greater pathogenicity of norovirus strains in 2003? A syndromic approach. Adv Dis Surveill. 2007;2:175. Abstract.

35. Harris JP, Edmunds WJ, Pebody R, Brown DW, Lopman BA. Deaths from norovirus among the elderly, England and Wales. Emerg Infect

Dis. 2008;14:1546 -1552.

36. Frenzen PD. Deaths due to unknown foodborne agents. Emerg Infect

Dis. 2004;10:1536 -1543.

37. Mead PS, Slutsker L, Dietz V, et al. Food-related illness and death in the United States. Emerg Infect Dis. 1999;5:607-625.

38. Smith Sehdev AE, Hutchins GM. Problems with proper completion and accuracy of the cause-of-death statement. Arch Intern Med. 2001;161: 277-284.

39. Brandt HE, Ooms ME, Deliens L, van der Wal G, Ribbe MW. The last two days of life of nursing home patients - a nationwide study on causes of death and burdensome symptoms in The Netherlands. Palliat Med.

2006;20:533-540.

40. Lindesmith LC, Donaldson EF, Lobue AD, et al. Mechanisms of GII. 4 norovirus persistence in human populations. PLoS Med. 2008;5:e31.

41. Kroneman A, Vennema H, van Duijnhoven Y, Duizer E, Koopmans M.

High number of norovirus outbreaks associated with a GGII. 4 variant in the Netherlands and elsewhere: does this herald a worldwide increase? Euro Surveill. 2004;12:041223.

42. Siebenga JJ, Vennema H, Renckens B, et al. Epochal evolution of GGII. 4 norovirus capsid proteins from 1995 to 2006. J Virol. 2007;81:9932-9941.

43. van Duynhoven YT, de Jager CM, Kortbeek LM, et al. A one-year intensified study of outbreaks of gastroenteritis in The Netherlands.

Epidemiol Infect. 2005;133:9 -21.

44. Verhoef L, Duizer E, Vennema $\mathrm{H}$, et al. Import of norovirus infections in the Netherlands and Ireland following pilgrimages to Lourdes, 2008—preliminary report. Euro Surveill. 2008;13:pii_19025. 
Asten, L. van, Siebenga, J., Wijngaard, C. van den, Verheij, R., Vliet, H. van, Kretzschmar, M., Boshuizen, H., Pelt, W. van, Koopmans, M. Unspecified gastroenteritis illness and deaths in the elderly associated with norovirus epidemics. Epidemiology: 2011, 22(3), 336-343

45. Siebenga JJ, Lemey P, Kosakovsky Pond SL, Rambaut A, Vennema H, Koopmans M. Phylodynamic reconstruction reveals norovirus GII. 4 epidemic expansions and their molecular determinants. PLoS Pathog. 2010;6:e1000884.

46. van Steenbergen J, Debast S, van Kregten E, van den Berg R, Notermans D, Kuijper E. Isolation of Clostridium difficile ribotype 027, toxinotype III in the Netherlands after increase in C. difficile-associated diarrhoea.

Euro Surveill. 2005;10:E050714.1.

47. Lambregts MM, Alleman MA, Ruys GJ, Groeneveld PH. Chronic norovirus infection in an immunocompromised patient_in Dutch_. Ned

Tijdschr Geneeskd. 2010;154:Ā1067.

48. Westhoff $\mathrm{TH}$, Vergoulidou M, Loddenkemper $\mathrm{C}$, et al. Chronic norovirus infection in renal transplant recipients. Nephrol Dial Transplant.

2009;24:1051-1053.

\section{TABLES AND FIGURES}

\begin{tabular}{|c|c|c|c|c|c|}
\hline & $\begin{array}{l}\text { Time } \\
\text { Period }\end{array}$ & $\begin{array}{l}\text { National } \\
\text { Coverage }^{2}\end{array}$ & Description & Source & Codes or Pathogens \\
\hline Norovirus surveillance data & 1994-2006 & $\begin{array}{l}\text { National (but } \\
\text { underreported) }\end{array}$ & $\begin{array}{l}\text { Passive reporting of outbreaks by } \\
\text { health services and food } \\
\text { inspectorates }\end{array}$ & $\begin{array}{l}\text { Norovirus outbreak surveillance } \\
\text { system }\end{array}$ & Norovirus \\
\hline General practitioner data & $2001-2006$ & $2 \%$ & $\begin{array}{l}\text { Signs, symptoms, and prescribed } \\
\text { medication at: surgery visits, } \\
\text { telephone calls, and home } \\
\text { visits }\end{array}$ & $\begin{array}{l}\text { Netherlands Information Network } \\
\text { of General Practice (a sentinel } \\
\text { system) }\end{array}$ & $\begin{array}{l}\text { ICPC-1: D10, D11, D73 } \\
\text { Vomiting, diarrhea, suspected gastrointestinal } \\
\text { infection }\end{array}$ \\
\hline Hospital discharge diagnoses & 1999-2006 & $>95 \%$ & $\begin{array}{l}\text { Main discharge diagnosis and } \\
\text { secondary diagnoses, with } \\
\text { hospitalization and discharge } \\
\text { dates }\end{array}$ & Dutch National Medical Register & $\begin{array}{l}\text { ICD9: } 0086-0093+0059+5589 \text { : } \\
0086 \text {, Enteritis due to specified virus } \\
\text { 0089: Enteritis viral, not elsewhere classified } \\
\text { 009: Ill-defined intestinal infections: } \\
\text { 0090: Infectious colitis, enteritis, and } \\
\text { gastroenteritis } \\
\text { 009.1: Colitis, enteritis, and gastroenteritis of } \\
\text { presumed infectious origin } \\
\text { 009.2: Infectious diarrhea } \\
\text { 009.3: Diarrhea of presumed infectious origin } \\
\text { 0059: Food poisoning, unspecified } \\
\text { 5589: Other and unspecified noninfectious } \\
\text { gastroenteritis and colitis }\end{array}$ \\
\hline Causes of death & 1999-2006 & $100 \%$ & $\begin{array}{l}\text { Date and cause of death (primary } \\
\text { and secondary causes) }\end{array}$ & Statistics Netherlands & $\begin{array}{l}\text { ICD 10: A08, A09 } \\
\text { Viral and other specified intestinal } \\
\text { infections } s^{\mathrm{b}} \text {; diarrhea and gastroenteritis of } \\
\text { presumed infectious origin }\end{array}$ \\
\hline $\begin{array}{l}\text { Classical laboratory } \\
\text { surveillance }\end{array}$ & $1999-2006$ & $\begin{array}{l}\text { Common viruses: } \\
38 \%-73 \% \\
\text { Common bacteria: } \\
50 \%-100 \%\end{array}$ & $\begin{array}{l}\text { Positive results of diagnostic } \\
\text { testing }\end{array}$ & $\begin{array}{l}\text { Weekly Sentinel Surveillance } \\
\text { System of the Dutch Working } \\
\text { Group on Clinical Virology }\end{array}$ & $\begin{array}{l}\text { Rotavirus, Salmonella, Shigella, } \\
\text { Campylobacter, influenza, respiratory } \\
\text { syncytial virus }\end{array}$ \\
\hline
\end{tabular}

Percentage of the total population in the Netheriands.

(he majocity was reported as "viral enteritis not elsewhere specified"

ICPC indicates Intemational Classification of Primary Care; ICD9, Intemational Classification of Diseases, ninth revision; ICD10, Intemational Classification of Diseases and Related Health Problems, tenth revision.

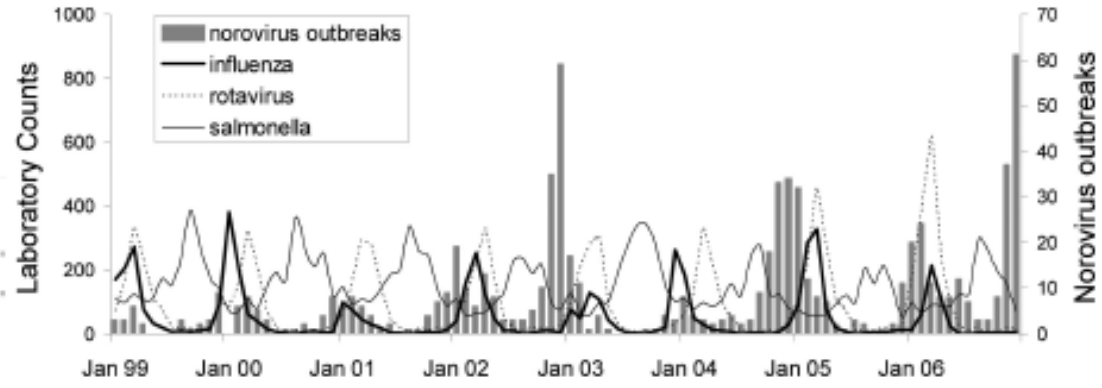

FIGURE 1. Monthly trends in norovirus outbreaks, and laboratory-based trends in influenza, rotavirus, and $\mathrm{Sal}$ monell $a$, in the Netherlands from 1999 to 2006. Shigella and Campylobacter not shown; like Salmonella, they peak in the summer. 
Asten, L. van, Siebenga, J., Wijngaard, C. van den, Verheij, R., Vliet, H. van, Kretzschmar, M., Boshuizen, H., Pelt, W. van, Koopmans, M. Unspecified gastroenteritis illness and deaths in the elderly associated with norovirus epidemics. Epidemiology: 2011, 22(3), 336-343

TABLE 2. Model Parameters of Predictors of Unspecified Gastroenteritis in GP Consultations, Hospitalizations, and Deaths: Results From Regression Models in Persons 65 Years and Older

\begin{tabular}{|c|c|c|c|c|}
\hline $\begin{array}{l}\text { Unspecified Gastroenteritis } \\
\text { (Dependant Variable) }\end{array}$ & $\underset{\text { Period }}{\text { Time }}$ & $\begin{array}{c}\text { Model } \\
\text { Determinants" }\end{array}$ & $\begin{array}{l}\text { Optimal Lag } \\
\text { (in Weeks) }\end{array}$ & $\begin{array}{l}\text { Parameter Estimate } \\
\left(\text { Beta) }{ }^{\mathrm{c}} \text { (Wald 95\% CI) }\right.\end{array}$ \\
\hline \multirow{8}{*}{$\begin{array}{l}\text { Unspecified gastroenteritis } \\
\text { in GP consultations }{ }^{d}\end{array}$} & \multirow[t]{8}{*}{$2001-2006$} & Intercept & NA & $155.53^{\circ}(57.06 \text { to } 254.00)^{\circ}$ \\
\hline & & Linear trend & NA & $0.32^{\circ}(0.08 \text { to } 0.56)^{\circ}$ \\
\hline & & Sine & NA & $49.26^{\circ}(-18.77 \text { to } 117.29)^{\circ}$ \\
\hline & & Cosine & NA & $48.36^{\circ}(10.18 \text { to } 86.53)^{\circ}$ \\
\hline & & Norovirus & 0 weeks & $25.70^{\circ}(16.5 \text { to } 33.5)^{\circ}$ \\
\hline & & Rotavirus & 0 weeks & $2.61^{\circ}(1.31 \text { to } 3.91)^{\circ}$ \\
\hline & & Shigella & 2 weeks & $7.27^{\bullet}(1.69 \text { to } 12.84)^{\circ}$ \\
\hline & & Campylobacter & 4 weeks & $1.45^{\circ}(0.22 \text { to } 2.68)^{\circ}$ \\
\hline \multirow{9}{*}{$\begin{array}{l}\text { Unspecified gastroenteritis } \\
\text { in hospitalizations }\end{array}$} & \multirow[t]{9}{*}{ 1999-2006 } & Intercept & $\mathrm{NA}$ & $53.45(47.70$ to 59.21$)$ \\
\hline & & Linear trend & NA & $0.12(0.10$ to 0.13$)$ \\
\hline & & Sine & NA & $2.11(-1.22$ to 5.43$)$ \\
\hline & & Cosine & NA & $2.03(-0.75$ to 4.80$)$ \\
\hline & & Norovirus & 3 weeks & $2.15(1.57$ to 2.74$)$ \\
\hline & & Rotavirus & 0 weeks & $0.13(0.06$ to 0.21$)$ \\
\hline & & Shigella & 4 weeks & $0.48(0.14$ to 0.83$)$ \\
\hline & & Campylobacter & 0 weeks & $0.08(0.01$ to 0.16$)$ \\
\hline & & Influenza & 0 weeks & $0.09(0.01$ to 0.17$)$ \\
\hline \multirow{5}{*}{$\begin{array}{l}\text { Unspecified gastroenteritis } \\
\text { deaths }^{\mathrm{d}}\end{array}$} & \multirow[t]{5}{*}{ 1999-2006 } & Intercept & $\mathrm{NA}$ & $0.39(0.20$ to 0.58$)$ \\
\hline & & Linear trend & NA & 0.003 (0.002 to 0.004$)$ \\
\hline & & Sine & NA & $0.15(0.003$ to 0.31$)$ \\
\hline & & Cosine & NA & $0.18(0.01$ to 0.34$)$ \\
\hline & & Norovirus & 1 week & $0.14(0.08$ to 0.21$)$ \\
\hline
\end{tabular}

shown are parameter estimates from a multivariate regression model that included a constant, a linear component, and a secsonal trend (sine and cosine terms) and significant pathogens.

${ }^{b}$ Given in number of weeks previous to the outoome variable. NA indicates not applicable (lags were not evaluated for the intercept, linear, sine, and cosine terms)

The number of patients $\alpha$ deaths associated with 1 registered norovinus outbreak.

dUnspecified gastroenteritis: unspecified gastreenteritis of possible viral origin (for GP consultations: ICPC code D73, for hospitalizations: ICD9 code $0086-0093+0059+5589$, for deaths: ICD10 codes: A08-A09 registered as either primary or secondary death cause).

"Beta and CI from the model (based on GP sentinel data with a coverage of $2 \%$ of the total population) were multiplied by 50 to estimate the beta and $\mathrm{CI}$ for the total population.

TABLE 3. Estimated Unspecified Gastroenteritis Diagnoses in the Elderly (GP Consultations, Hospitalizations, and Deaths), Which are Attributed ${ }^{\mathbf{a}}$ to Norovirus Outbreaks

\begin{tabular}{|c|c|c|c|c|}
\hline \multirow[b]{2}{*}{ Season $^{b}$} & \multirow[b]{2}{*}{$\begin{array}{c}\text { Norovirus } \\
\text { Activity } \\
\text { No. Outbreaks }\end{array}$} & \multicolumn{3}{|c|}{$\begin{array}{l}\text { Morbidity and Mortality Attributed } \\
\text { to Norovirus Outbreak Activity }\end{array}$} \\
\hline & & $\begin{array}{c}\text { uGE } \text { CP }^{\text {A }} \\
\text { Attributed }^{a} \\
\text { to Norovirus }\end{array}$ & $\begin{array}{c}\text { uGE }^{c} \\
\text { Hospitalizations } \\
\text { Attributed } \\
\text { to Norovirus }\end{array}$ & $\begin{array}{l}\text { uGE } E^{e} \text { Deaths } \\
\text { Attributed } \\
\text { to Norovirus }\end{array}$ \\
\hline $1999 / 2000$ & 27 & & 58 & 4 \\
\hline $2000 / 2001$ & 19 & & 41 & 3 \\
\hline $2001 / 2002$ & 60 & 1542 & 129 & 8 \\
\hline $2002 / 2003$ & 128 & 3290 & 275 & 18 \\
\hline $2003 / 2004$ & 30 & 771 & 65 & 4 \\
\hline $2004 / 2005$ & 148 & 3804 & 318 & 21 \\
\hline $2005 / 2006$ & 100 & 2570 & 215 & 14 \\
\hline
\end{tabular}

aCakulated by multiplying the number of reported outbreaks with the estimated beta for norovirus (as derived from the regression models).

'Including only complete years runing from July to June. 1998-1999 and 20062007 seasons not shown, as both include only half a year of data (data were available from 1 January 1999 to 31 December 2006).

'UGE: unspecified gastroenteritis of possible viral origin (for GP consultations: ICPC code D73, for hospitalizations: ICD9 codes 0086-0093 + 0059 + 5589, for deaths: ICD10 codes: A08-A09 registered as either primary or secondary death cause). 
Asten, L. van, Siebenga, J., Wijngaard, C. van den, Verheij, R., Vliet, H. van, Kretzschmar, M., Boshuizen, H., Pelt, W. van, Koopmans, M. Unspecified gastroenteritis illness and deaths in the elderly associated with norovirus epidemics. Epidemiology: 2011, 22(3), 336-343

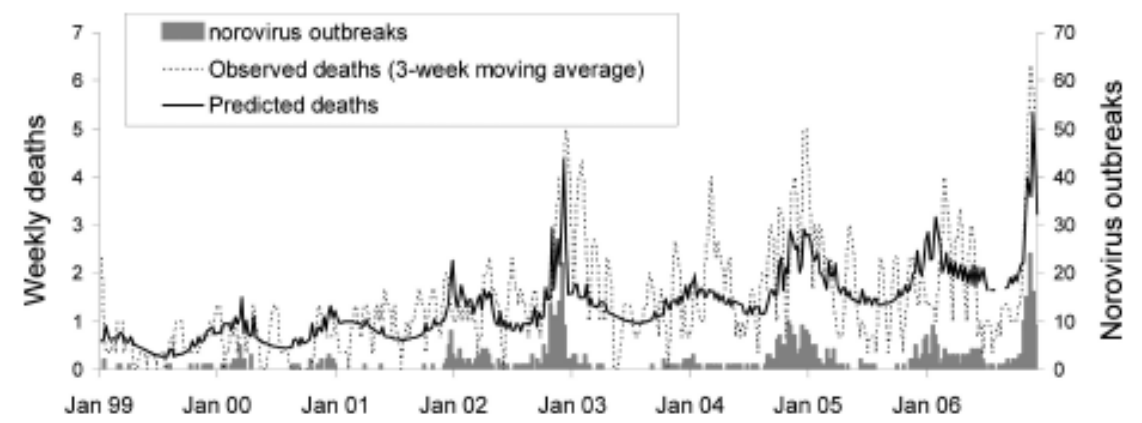

FIGURE 2. Modeled weekly deaths due to unspecified gastroenteritis in Dutch elderly (65+ years of age), 1999-2006. Observed deaths are based on the Dutch national death registry: any death cause (primary or secondary) coded as viral, intestinal (ICD10: A08), or gastroenteritis of presumed infectious origin (ICD10: A09), and plotted as the 3-week moving average. Predicted deaths are based on coefficients obtained from a regression model, which included an intercept, a linear increasing trend with time, a cyclical seasonal trend (a sine and cosine term), and total norovirus outbreaks (1 week previously) as explanatory variables (norovirus outbreaks not available stratified by age). 